\title{
Correction to: Wind of change: zooarchaeological approach to the Middle-Upper Palaeolithic transition in Cova Gran of Santa Linya (Lleida, south-eastern Pre-Pyrenees)
}

\author{
Sofía C. Samper Carro ${ }^{1,2,3} \cdot$ Jorge Martínez-Moreno ${ }^{3} \cdot$ Rafael Mora $^{3}$ \\ Published online: 19 September 2020 \\ (C) Springer Nature Switzerland AG 2020
}

\section{Correction to: Journal of Paleolithic Archaeology https://doi.org/10.1007/s41982-020-00066-1}

The original version of this article unfortunately contained a mistake. Table 3 is now presented here correctly.

The original article has been corrected.

The original article can be found online at https://doi.org/10.1007/s41982-020-00066-1

Sofía C. Samper Carro

sofia.samper@anu.edu.au

1 School of Archaeology and Anthropology, College of Arts and Social Sciences, The Australian National University, Canberra 2601, Australia

2 Department Archaeology \& Natural History, School of Culture, History and Language, College of Asia \& the Pacific, The Australian National University, Canberra 2601, Australia

3 Centre d'Estudis del Patrimoni Arqueologic (CepArqUAB), Facultat de Lletres-Edifici B, Universitat Autonoma de Barcelona, 08193 Bellaterra, Spain 


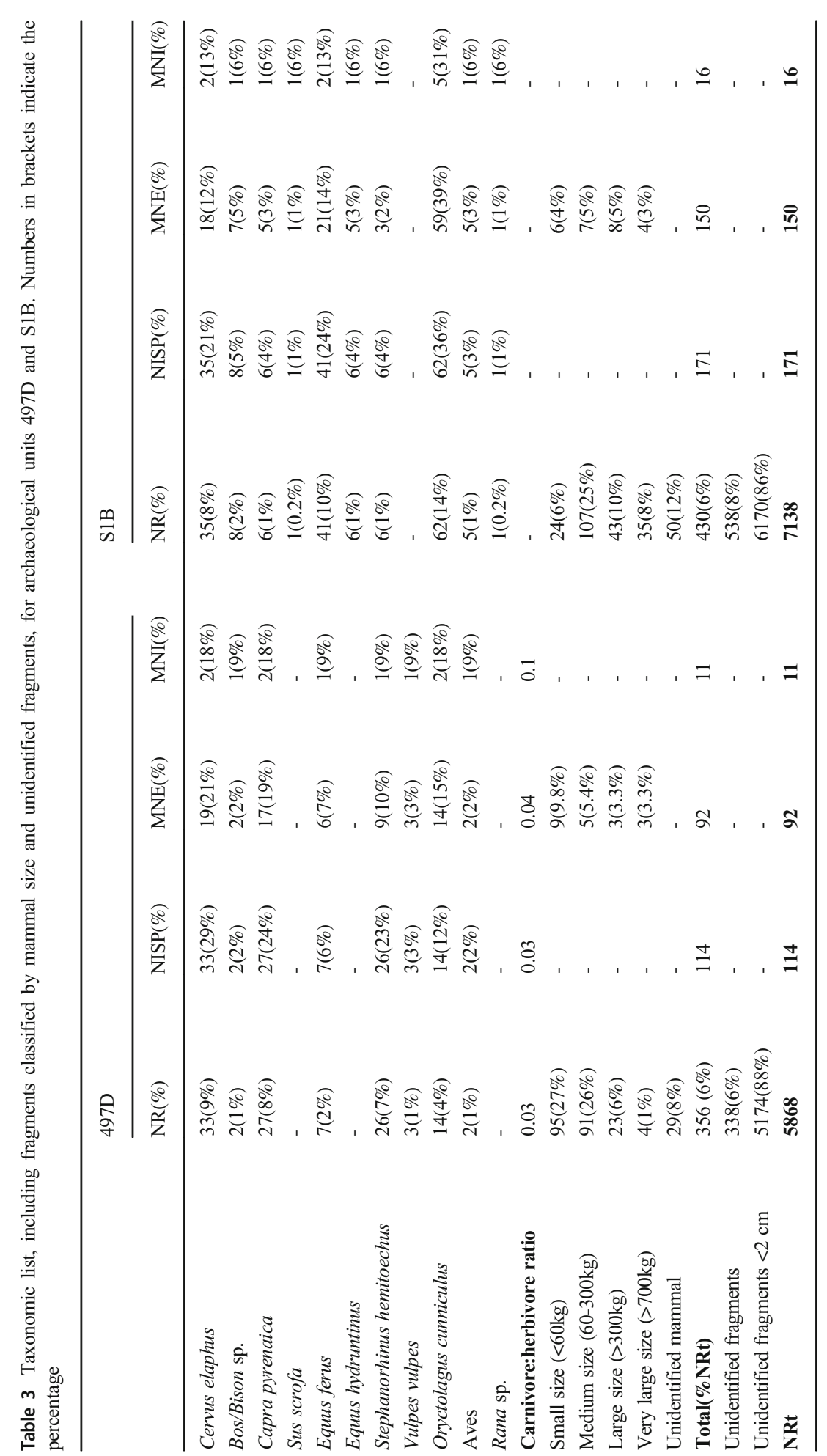

